\title{
Introducing small storage capacity at residential PV installations to prevent overvoltages
}

\author{
J. Cappelle*, J. Vanalme ${ }^{\dagger}$, S. Vispoel ${ }^{*}$, T. Van Maerhem ${ }^{*}$, B. Verhelst ${ }^{\dagger}$, C. Debruyne ${ }^{\dagger}$ and J. Desmet ${ }^{\dagger}$ \\ ${ }^{*} \mathrm{KaHo}$ Sint-Lieven University College \\ Department industrial engineering \\ Gebr. De Smetstraat 1 \\ B-9000 Gent, Belgium \\ Email: jan.cappelle@kahosl.be \\ $\dagger_{\text {HOWEST }}$ \\ Department GKG \\ Graaf Karel de Goedelaan 5 \\ B-8500 Kortrijk, Belgium \\ Email: johan.vanalme@howest.be
}

\begin{abstract}
Low voltage distribution feeders are designed for unidirectional energy supply from transformer to consumer. However, the implementation of small-scale PV production units on local utilities may result in bidirectional energy flows. The simultaneous power injection at sunny moments may cause a serious voltage rise along the feeder. These overvoltages may not only damage critical loads but also switches PV inverters off causing loss of green energy at the most productive moments. This paper presents a method to limit the voltage rise by introducing small battery buffers at local production sites. A smart inverter decides whether the PV energy is injected in the grid or buffered in the batteries. The relation between battery buffer size and overvoltage reduction is presented for a typical Belgian residential distribution feeder. The influence of the buffer along the feeder is calculated by working with synthetic load profiles and solar irradiation data.
\end{abstract}

\section{INTRODUCTION}

In recent years the number of photovoltaic (PV) installations in residential areas has drastically increased in Belgium. The main reason is the rewarding by the Flemish government of every produced (PV-)megawatthour with a green certificate of 350 Euro. The number of green certificates paid out has increased from 1356 in 2006 to 459.518 in 2010 [1]. This massive introduction of distributed generation causes some challenges for the distribution network operator such as reverse power flow, increased shortcircuit power, unintentional islanding, selectivity of protections, stability problems and power quality issues like harmonic distortion and voltage rise [2][3].

This paper will focus on the problem of the voltage rise. Overvoltages may not only damage critical loads but also swithes PV inverters off causing loss of green energy at the most productive moments [4]. There are several overvoltage limitation methods possible. These are discussed in section II. The method presented in this paper is the introduction of energy buffering at local production sites. Firstly, the overvoltage due to the introduction of PV panels is quantified for the single phase asymmetrical situation as well as for a three phase symmetrical injection. Time as well as location dependency of the overvoltage is given. Secondly, the influence of battery buffering on the probability of overvoltage will be discussed.

\section{Methods for OVervoltage limitation}

The European standard EN50160 specifies that 95\% of the 10 minute average RMS voltage at medium and low voltage level must be within $\pm 10 \%$ of the nominal voltage. In section III will be discussed how probable this is for a low voltage feeder with a considerable amount of distributed generation. First of all several suggested solutions for the overvoltage problem are discussed.

\section{A. Reactive power injection}

In high voltage (HV) and medium voltage (MV) networks it is common to control the voltage by reactive power injection. This strategy is no longer evident in the low voltage (LV) distribution networks, because of the high $\mathrm{R} / \mathrm{X}$ ratio. Typical values for medium voltage (MV) networks are between 0.02 and 0.3 [5]. The values for low voltage feeders may reach a value above 3 [6]. Simulations showed that the overvoltage due to the injection of 13 times $1 \mathrm{~kW}$ on a typical distribution feeder (see section III-B) could only be compensated by an injection of 13 times $1 \mathrm{kVAr}$. This is considered to be unacceptably high.

\section{B. Automatic tapchanger (ULTC)}

At low voltage distribution feeders with a considerable voltage drop, the tap setting of the transformer is often set about 5\% above the nominal voltage. This compensates the voltage drop in case of unidirectional power flow, but makes overvoltage worse in case of power injection on the feeder. In unidirectional medium voltage distribution feeders with considerable power flow fluctuations, the changing of the tap of a transformer under load via ULTC is common. Adaptations for voltage stabilization in the presence of distributed generation can be found in literature but are not always sufficient to stabilize the entire distribution network [7],[8],[9]. 


\section{Active power control by influencing the MPPT}

In case of gridcoupled photovoltaic installations, overvoltage could be prevented by limiting the power injection at sunny peak moments. This could be done by enabling the Maximum Power Point Tracking (MPPT) of the inverters to leave the maximum power point if the risk of an overvoltage switch-off gets real. This leads to the loss of green power, but may be preferred over the loss of the complete PV installations due to the overvoltage protection of the inverters. An extra problem in this solution is the injustice that the one who has the extra MPPT feature looses green power and certificates, while the classic installation gets the benefits of the lowered voltage.

\section{Active power control by energy buffering}

Instead of accepting the loss of green power, the buffering of energy that cannot be injected seems to be a more elegant way to limit overvoltage. This requires a smarter inverter system that injects as much active power as possible into the grid, but stores some energy locally during periods with high risk of overload. This project wanted to investigate what size of energy buffer is required and which power electronic solutions do exist to enable this method in a distribution feeder in residential area.

\section{QUANTIFICATION OF OVERVOLTAGES ON A DISTRIBUTION FEEDER}

\section{A. Maximum power injection}

To determine the maximum power injection allowed without exceeding $U_{\text {nom }}+10 \%$, the equivalent power injection method is used. This method states that several single phase injections along the feeder can be replaced by a single power injection at the end of the feeder, resulting in the same overvoltage at the end of the feeder. The equivalent power is given by expression 1:

$$
P_{e}=\frac{\sum_{i} P_{i} \cdot L_{i}}{L}
$$

where $P_{i}$ is injected power at a distance $L_{i}$. The product of equivalent power $P_{e}$ and the total length of the feeder $L$ is called the electric momentum. The momentum required to reach the $10 \%$ overvoltage $(=253 \mathrm{~V})$ is given in table I for different low voltage cable types.

TABLE I

REQUIRED MOMENTUM TO REACH $10 \%$ OVERVOLTAGE FOR DIFFERENT CONFIGURATIONS [4]

\begin{tabular}{|l|l|l|}
\hline Cable Type & $\begin{array}{l}\text { Power Injec- } \\
\text { tion }\end{array}$ & $\begin{array}{l}10 \% \text { Overvoltage } \\
\text { (per phase) Electric } \\
\text { Momentum }\end{array}$ \\
\hline \hline EAXVB $4 \times 150$ & single phase & $P_{e} L=6690 \mathrm{kWm}$ \\
\hline $\mathrm{BXB} 3 \times 95+54$ & single phase & $P_{e} L=2700 \mathrm{kWm}$ \\
\hline EAXVB $4 \times 150$ & three phase & $P_{e} L=7725 \mathrm{kWm}$ \\
\hline $\mathrm{BXB} 3 \times 95+54$ & three phase & $P_{e} L=4272 \mathrm{kWm}$ \\
\hline
\end{tabular}

\section{B. Typical Belgian low voltage feeder}

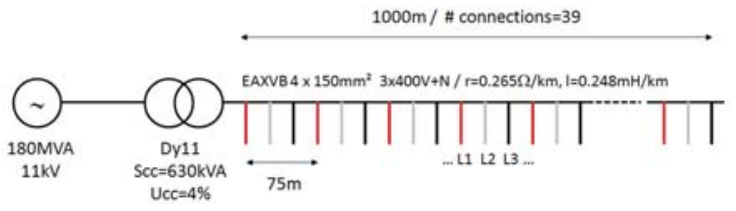

Fig. 1. Representative Belgian residential distribution feeder

The probability of overvoltage occurrence will be investigated on a low voltage feeder for a hypothetical but representative Belgian residential area with a considerable number of PV installations. The main characteristics of the feeder are given in figure 1 . The medium voltage is transformed to a $3 \times 400 \mathrm{~V}+N$ low voltage by a $630 \mathrm{kVA}$ transformer. The feeders are EAXVB $4 \times 150 \mathrm{~mm}^{2}$ with a total length of $1000 \mathrm{~m}$. The 39 connected houses are equally divided over the three phases. The distance between houses is about $25 \mathrm{~m}$. The overvoltage on this feeder will be studied assuming a complete symmetrical situation: injection as well as consumption are considered to be equally distributed between the three phases. This allows us to use a single phase star equivalent with 13 connected houses for the simulations as illustrated in figure 5 . The overvoltage in the case of single phase injection would be even higher because the asymmetry will lead to a homopolar current and a resulting homopolar voltage drop. This homopolar voltage drop may be bigger than the voltage drop in the line wire, because many rural distribution networks are equipped with a neutral wire with smaller section. This effect is clearly visible looking at table I.

For the simulations, 5 types of users are introduced and spread along the distribution feeder.

- Type 1 is a household with an average energy consumption of $4000 \mathrm{kWh} /$ year but no solar panels

- Type 2 is a household with an average energy consumption of $4000 \mathrm{kWh} /$ year and $4.7 \mathrm{kWp}$ solar panels to cover their yearly consumption

- Type 3 is an energy-efficient household of $3000 \mathrm{kWh} / \mathrm{year}$ and $3.5 \mathrm{kWp}$ solar panels to cover their yearly consumption

- Type 4 is an energy-intensive household of $5000 \mathrm{kWh} / \mathrm{year}$ and $5.9 \mathrm{kWp}$ solar panels to cover their yearly consumption

- Type 5 is a household with an average energy consumption of $4000 \mathrm{kWh} /$ year but with a time pattern different from a type 1 household and $4.7 \mathrm{kWp}$ solar panels to cover their yearly consumption

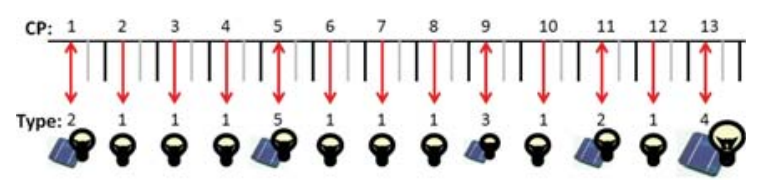

Fig. 2. Types of connected household in $L_{1}$ of the low voltage feeder 
The types of the 13 households connected to line $1\left(L_{1}\right)$ are given on figure 2. The sizing of the PV installations is done with the rule of thumb that is used by many PV installers: one should install enough solar panels to cover the own electrical energy consumption. The yearly yield of a PV installation in Belgium is considered to be about $850 \mathrm{kWh} / \mathrm{kWp}$. So to cover $4000 \mathrm{kWh}$, one needs to install $4.7 \mathrm{kWp}$.

The percentage of PV penetration is $38 \%$ in the simulated area. In this case, the equivalent installed power momentum is $12700 \mathrm{kWm}$ which is considerably more than the value of $7725 \mathrm{kWm}$ (see table I) that is required to reach the maximum voltage at the end of the feeder. It is expected that the combination of high solar irradiation and low consumption should frequently lead to overvoltage along the feeder.

\section{Synthetic profiles}

The quantification of the overvoltage will be done using synthetic year profiles for the load power as well as for the injected power. These profiles are discussed below.

1) Synthetic load profile: The power consumption distribution is obtained from the synthetic load profiles (SLP) as defined by the Flemish regulator of the electricity market VREG [10]. The power consumption of an average household

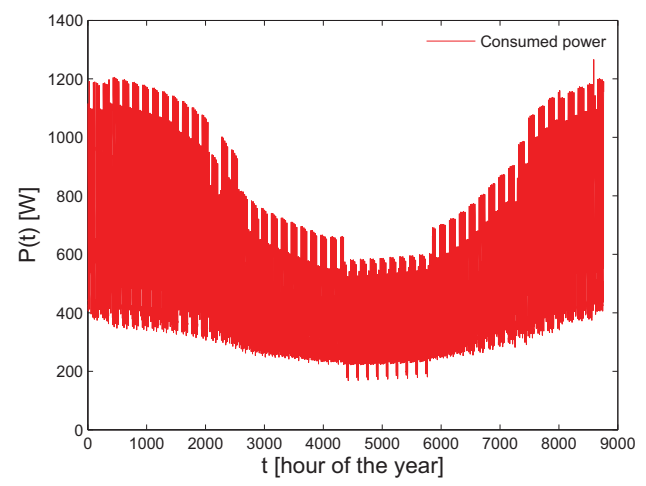

Fig. 3. Average quarter power demands of an average household

is given on a 15 minute basis for a whole year. The values of the power are average power demands during each quarter. The profile is given in figure 3 .

2) Synthetic solar power injection profiles: The power injection profiles are derived from average irradation data of the Meteonorm database on an hourly basis. The power of the PV installations is assumed to be proportional to the solar irradiation. The solar power yield for a standard year for a $4.7 \mathrm{kWp}$ PV installation in the Flemish region is given in figure 4.

Because the synthetic power profiles are composed by average quarter values, the real powerpeak demand/injection or the real instantaneous overvoltage cannot be found in this way.

\section{Voltage profiles along the feeder}

The simulations are exercised on the single phase equivalent of figure 5 where $V_{\text {grid }}$, the phase voltage at the transformer

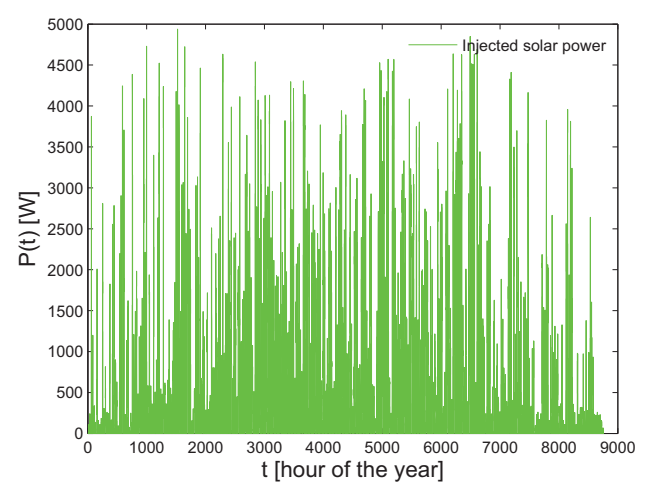

Fig. 4. Solar power yield of a 4.7kWp PV-installation in the Flemish region

is set $5 \%$ above the nominal value of $230 \mathrm{~V}$, which is common to compensate for the voltage drop in classical distribution systems.

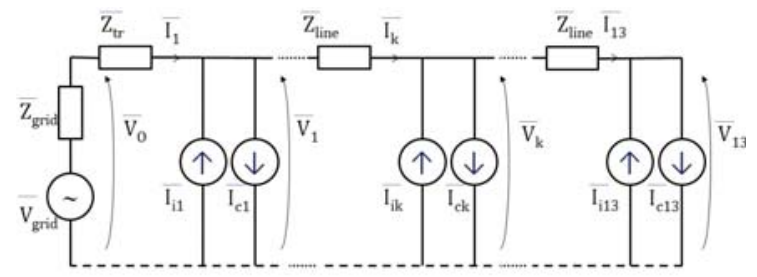

Fig. 5. Star equivalent scheme of the distribution feeder

The values of the short circuit impedance $\bar{Z}_{\text {grid }}$ of the grid, the transformer impedance $\bar{Z}_{t r}$ and the line impedance $\bar{Z}_{\text {line }}$ are given in table II. The power consumption and demand are

TABLE II

IMPEDANCE VALUES OF THE STAR EQUIVALENT

\begin{tabular}{|c|c|}
\hline $\bar{Z}_{\text {grid }}$ & $0.882+j 0.551$ \\
\hline $\bar{Z}_{t r}$ & $1.7+j 10$ \\
\hline $\bar{Z}_{\text {line }}$ & $20.4+j 6$ \\
\hline
\end{tabular}

modelled as voltage dependent current sources. The currents $\bar{I}_{i}$ and $\bar{I}_{c}$ of figure 5 are derived from the complex injected power $\bar{S}_{i}$ and the complex consumed power $\bar{S}_{c}$ respectively. The $\cos \varphi$ of the households are assumed to be 0.95. Apart from the first and last household, for each connection point $\mathrm{k}$ the application of Kirchoff's laws states:

$$
\begin{aligned}
& \bar{V}_{k-1}-\bar{V}_{k}-\bar{Z}_{\text {line }} \bar{I}_{k}=0 \\
& \frac{\bar{S}_{c}{ }^{*}}{{\overline{V_{k}}}^{*}}-\frac{\bar{S}_{i}{ }^{*}}{\bar{V}_{k}{ }^{*}}-\bar{I}_{k-1}+\bar{I}_{k}=0
\end{aligned}
$$

Similar reasoning for the first and last connection results in a set of 27 nonlinear equations in the line currents $I_{k}$ and the voltages $V_{k}$. Solving this set for every quarter of the year gives the voltage year profile at every connection point. 
The voltage profiles for 4 connection points $\left(V_{1}, V_{5}, V_{9}, V_{13}\right)$ during the period 8-30 september is presented in figure 6 . In

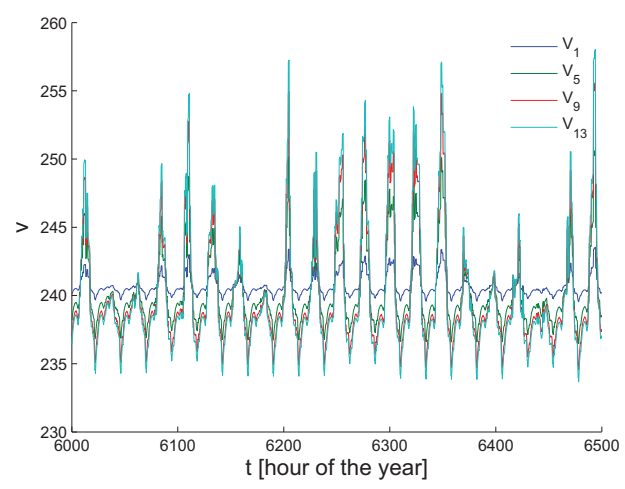

Fig. 6. Voltage profiles at 4 connection points in the month of september

this period there are already 7 days where the overvoltage reaches the maximum value of the EN50160. The relative occurrence of the overvoltage is given for all the connection points in figure 7 . The voltage at the end of the feeder will be over the $253 \mathrm{~V}$ maximum during $1.5 \%$ of the time. This seems to be better than expected but when PV inverters switch off at these overvoltage periods, the loss of green energy is considerable. The overvoltage periods are happening at the brightest days when the solar panels are massively injecting. The $1.5 \%$ overvoltage periods represent $12.5 \%$ of the yearly

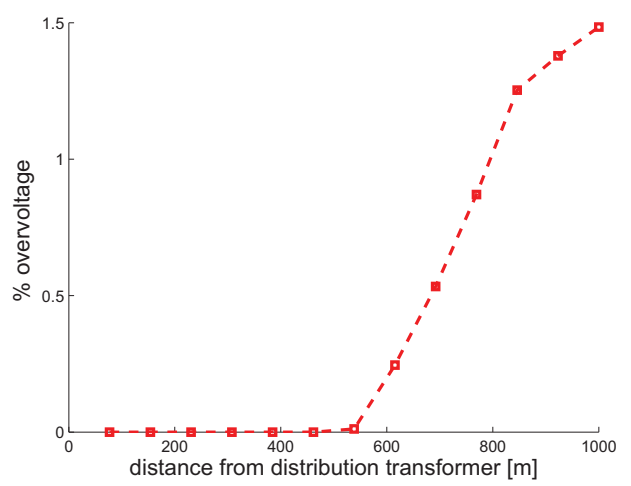

Fig. 7. Percentage of the time with overvoltages along the feeder

solar energy yield! The switch-offs of the PV inverter mean an energy loss of $625 \mathrm{kWh} /$ year, or a money loss of $€ 330 /$ year for the household at the end of the feeder.

\section{INTRODUCING ENERGY BUFFERING}

\section{A. Power injection limitation and buffer size}

The set-up of this research was to investigate to what extend the introduction of energy buffering could reduce the frequency and voltage level of the overvoltages. The idea is to put energy storage capacity at every household with a PV installation. The distribution network operator could limit the maximum power injection at distribution feeders with overvoltage problems. This limitation could be a fixed power level, or a power level related to the installed PV. In

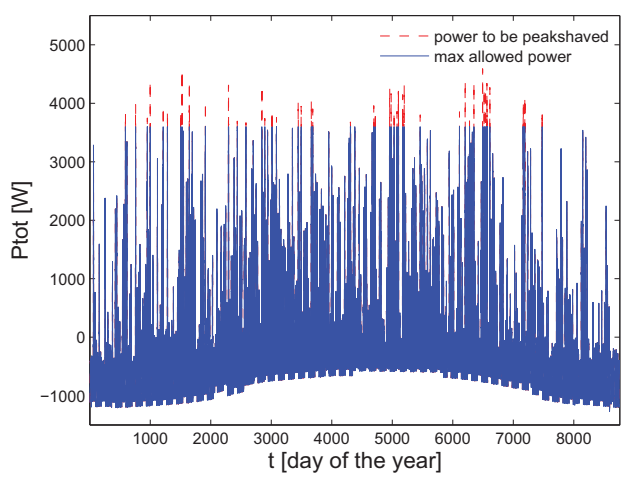

Fig. 8. Net limited injected power for a type 2 household

this paper the second option will be discussed. The power limitation is illustrated for a household of type 2 (definition in section III-B) with an electricity consumption of $4000 \mathrm{kWh}$ and a PV installation of $4.7 \mathrm{kWp}$ which covers the yearly consumption. Figure 8 shows the net (solar minus consumed) power that will be injected if the max power level is set to 3600W (single phase). The dashed red line in figure 8 shows the power that should be peakshaved. The time integration of this power overshoot gives the energy that should be stored. This surplus energy will be stored during the solar peak moments, and delivered to the distribution grid during night. The overvoltage risk during night is unexistant, even if all PV households uncharge their batteries with the surplus energy. The energy storage capacity that is required to peakshave a type 2 household at $3600 \mathrm{~W}$ is given as a histogram in figure 9. The energy buffer will be needed 31 days of the year. The maximum storage capacity required is $2 \mathrm{kWh}$. Changing the maximum power limit influences the required buffer size. Table III shows the influence of the maximum power limit on the required maximum storage capacity for one day. The last row of this table expresses the ratio of the maximum storage capacity to the average daily PV energy production.

\section{B. Influence of energy buffering on overvoltage}

The year profiles of the voltage along the feeder are now recalculated with a power injection limit imposed at all households with PV installations. So, each household with solar panels gets a certain battery buffer. The storage capacity installed is determined as a percentage of the estimated average daily PV production. The battery buffer will only be used during the days that the PV power exceeds the power limit. In our case this means 31 days for a limit of $3600 \mathrm{~W}$ for a $4.7 \mathrm{kWp}$ installation. The calculations are done for all the injection limits of table III. The frequency of occurrence and the peak 


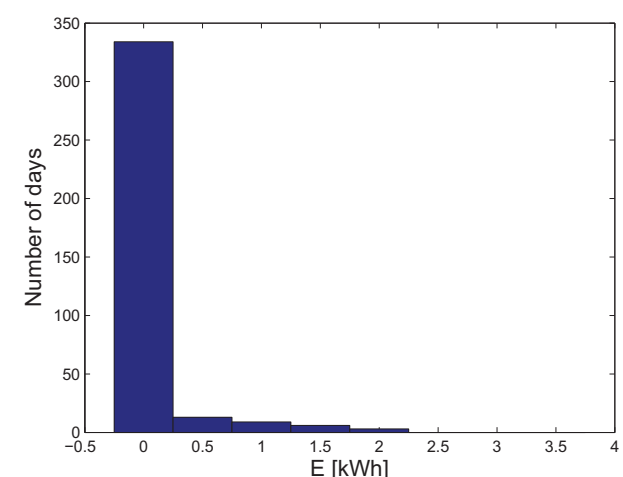

Fig. 9. Histogram of the required energy buffer for peakshaving a type 2 households on $3600 \mathrm{~W}$

TABLE III

INFLUENCE OF POWER INJECTION LIMIT ON THE REQUIRED BUFFER SIZE FOR A 4.7KWP INSTALLATION WITH A TYPICAL BELGIAN SOLAR IRRADIATION PROFILE

\begin{tabular}{|l|cccccccc|}
\hline $\begin{array}{l}\text { Power injection } \\
\text { limit }[\mathrm{kW}]\end{array}$ & $\infty$ & 4.0 & 3.8 & 3.6 & 3.5 & 3.4 & 3.3 & 3.2 \\
\hline \hline $\begin{array}{l}\text { Max storage } \\
\text { capacity [kWh] } \\
\% \text { of daily PV }\end{array}$ & 0 & 0.99 & 1.4 & 2.0 & 2.4 & 2.8 & 3.2 & 3.7 \\
yield & 10 & 13 & 18 & 22 & 26 & 29 & 34 \\
\hline
\end{tabular}

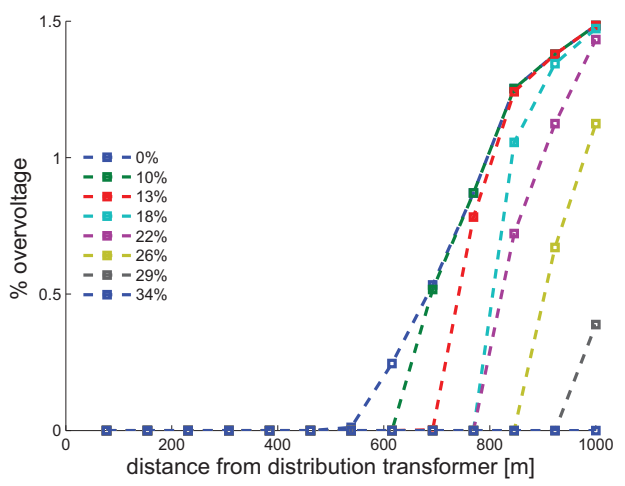

Fig. 10. Percentage of time with overvoltage at different locations and for different energy buffer sizes

of the overvoltage are decreasing when the relative buffer size is increasing. This is illustrated in figure 10. This figure gives the percentage of the time with overvoltage $(>253 \mathrm{~V})$ as a function of the location on the feeder and the relative size of the energy buffer. The location is given as a distance in meters from the distribution transformer.

The impact of the storage capacity is really visible from a storage capacity of $18 \%$ of the average daily PV production. The overvoltage at three connection points (CP8, CP9 and
CP10 from figure 2) is elimininated in this case. However, at the end of the feeder the overvoltage remains. Increasing the storage capacity to $26 \%$ reduces the percentage of time of overvoltage at the end of the feeder from $1.5 \%$ to $1.1 \%$ (see figure 10). The corresponding loss of PV energy for the household at the end of the feeder is reduced from $500 \mathrm{kWh}$ to $240 \mathrm{kWh}$ each year.

The simulations demonstrate that to eliminate all overvoltages a buffer size of $34 \%$ would be needed, which means a maximum storage capacity of $3.7 \mathrm{kWh}$ for a type 2 household.

\section{Power ELECTRONIC SOLUTION}

Of course today's standard PV inverters are not equipped for the introduction of a battery buffer. Although for the single phase situation as is described in this paper, the hardware should not differ too much of a standard three phase inverter, where two inverter legs are used to invert the DC and make the grid connection. The third inverter leg should control the bidirectional current to charge and discharge the battery buffer. The unidirectional energy of the solar panels can be controlled by the break chopper which can be found in most three phase inverters. This flexible all-in-one solution and its control is extensively discussed in reference [11].

\section{CONCLUSION}

This paper investigates the possibilities to prevent overvoltages $(>253 \mathrm{~V})$ on a low voltage distribution feeder due to the simultaneous power injection of a considerable number of PV installations. This overvoltage may be overcome by introducing limited local energy buffering at the location of power injection. The energy buffer will only be used during solar peak moments when the injected power exceeds a predefined power limit. Simulations on a representative Belgian low voltage feeder show that the effect of buffering gets visible if the storage capacity is more than $18 \%$ of the average estimated daily PV production of the installation. An energy buffer that is able to buffer $34 \%$ of the average daily PV energy eliminates all overvoltages, while it only makes about 30 charge/discharge cycles a year. The cost of the power electronics and controller to implement this strategy will be considerable. But for this price, green energy losses are reduced, PV installation possibilities in rural areas are raised and the PV owner gets an energy buffer that may serve as uninterruptable power supply.

\section{REFERENCES}

[1] Vlaamse Regulator voor Elektriciteit en Gasmarkt, www.vreg.be/sites/default/.../aantal_uitgereikte_groenstroomcertificaten.doc.

[2] M. Mes, G. M. A. Vanalme, J. Bongaerts, G. Verbong, and W. Kling, "Implementation of Distributed Generation in the Dutch LV Network - Self Supporting Residential Area," in Proceedings UPEC. Padova, Italy, september 2008.

[3] D. Popović, J. Greatbanks, M. Begović, and A. Pregelj, "Placement of distributed generators and reclosers for distribution network security and reliability," International Journal of Electrical Power \& Energy Systems, vol. 27(5-6), pp. 398-408, 2005.

[4] C. Debruyne, J. Desmet, J. Vanalme, G. Vanalme, and L. Vandevelde, "Maximum power injection acceptance in a residential area," in Proceedings ICREPQ. Granada, Spain, March 2010. 
[5] C. Prévé, Protection of Electrical Networks. London: ISTE, 2006.

[6] J. Desmet, C. Debruyne, J. Vanalme, and B. Verhelst, Implementatie van innovatieve duurzame energiebronnen en hun interactie op het distributienet. Howest-Lemcko, 2010.

[7] S. Liew and G. Strbac, "Maximising penetration of wind generation in existing distribution networks," in IEE Proceedings-Generation Transmission and Distribution, vol. 149, 2002, pp. 256-262.

[8] C. Masters, "Voltage rise: the big issue when connecting embedded generation to long $11 \mathrm{kV}$ overhead lines," Power Engineering Journal, vol. 16(1), pp. 5-12, 2002.

[9] F. Katiraei, C. Abbey, and R. Bahry, "Analysis of Voltage Regulation Problem for a $25 \mathrm{kV}$ Distribution Network with Distributed Generation." in IEEE Power Enginnering Society General Meeting, 2006.

[10] Vlaamse Regulator voor Elektriciteit en Gasmarkt, http://m.vreg.be/verbruiksprofielen-0.

[11] J. Cappelle, S. Vispoel, and T. V. Maerhem, "An all-in-one power electronic solution for the introduction of PV and storage for smart grids," in EPE, 2011 